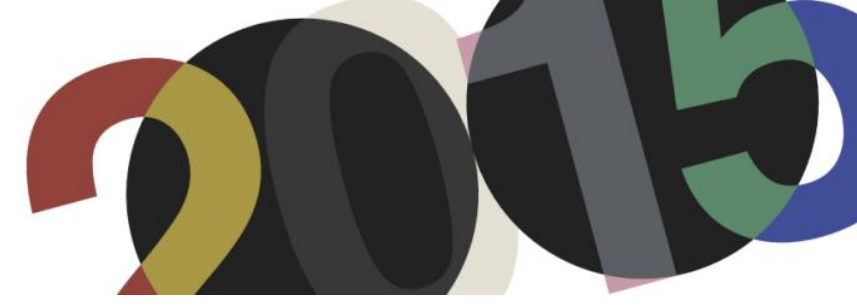

DOI: http://dx.doi.org/10.4995/LC2015.2015.792

\title{
Copy-Paste: Le Corbusier en OMA / Rem Koolhaas
}

\author{
R. del Valle González
}

Escuela Técnica Superior de Arquitectura de Madrid

\begin{abstract}
Resumen: La arquitectura que realiza OMA / Rem Koolhaas podría denominarse como un 'juego sabio de los volúmenes reunidos bajo la luz' disfrazados y entremezclados en la complejidad de los tiempos que vivimos, la de una arquitectura que debe reflejar nuestra sociedad. Para hacerlo posible, Rem parece 'calcar', paso a paso, la trayectoria lecorbuseriana, confundida y camuflada bajo hábiles mecanismos contemporáneos de 'Copy-Paste', vendiéndola al mejor postor como una 'nueva arquitectura' para los tiempos que están por venir. Pero el 'Copy-Paste' no es algo nuevo ni de ahora. Le Corbusier nos ha enseñado estos mecanismos de 'Copiar-Pegar' prácticamente en la totalidad de su obra, desde sus inicios hasta su madurez.
\end{abstract}

Abstract: The Architecture that OMA / Rem Koolhaas makes could be call like a 'the masterly interplay of masses brought together in light' disguised and interspersed with the complexity of the time that we are living, an architecture that must reflect our society. To make it possible, Rem appears to 'trace', step by step, the Le Corbusier's path, confused and camouflaged under skillful contemporary mechanisms of 'Copy-Paste', selling it to the highest bidder as a 'new architecture' for the times to come. However, the Copy-Paste' is not something new or now. Le Corbusier has taught us these mechanisms of "Copy-Paste" practically in all of his work, from his beginnings up to his maturity.

Palabras clave: Copy-Paste; Cita; Koolhaas; Estructura; Materia; Programas.

Keywords: Copy-Paste; Quote; Koolhaas; Structure; Materia; Programs.

\section{Introducción}

En el momento de revisar esta comunicación, leo un artículo en un diario de tirada nacional que lleva por título 'La guerra de las universidades contra el copy-paste' y que alerta del plagio, cada vez más recurrente por parte de los estudiantes, en los documentos académicos ${ }^{1}$, si bien la mayoría de las veces, éstos no son conscientes que la acción de copiar y pegar constituye una vulneración de la propiedad intelectual del autor del texto original.

Distinguir entre lo original y la copia, entre la interpretación de una realidad descrita por un autor -en forma de documento escrito, obra de arte o, en el terreno que nos ocupa, edificio o proyecto arquitectónico- y entre la imitación, alteración, manipulación o transformación que se somete al original por un segundo autor que haga que esta segunda obra goce de nueva autenticidad y, por tanto, no sea considerada una vulgar copia de la original, es una realidad que ha existido siempre, pero que hoy se encuentra sobre-intensificada gracias al potente desarrollo de las herramientas informáticas y la divulgación del conocimiento en una cultura global.

Sin duda, estudiando en profundidad la trayectoria de Koolhaas, podemos descubrir como su obra está claramente sustentada por la arquitectura lecorbuseriana, en forma y pensamiento. Koolhaas nunca lo dirá

\footnotetext{
${ }^{1}$ Otiniano Pulido, C: "La guerra de las universidades contra el copy-paste". En Economía, El País. 8 de junio de 2015. No he podido evitar la inclusión de esta referencia a última hora, pues pone en evidencia los temas que aquí se tratan.
} 
expresamente, pero su obra está plagada de citas, referencias, homenajes o, si se quiere, copias disfrazadas de Le Corbusier. Aunque no sólo: figuras del constructivismo ruso, referencias cinematográficas, Leodinov, Constant, Archigram o Mies van der Rohe formarán parte de su ideario ${ }^{2}$, si bien no forma parte del interés de este texto, que se centrará, como desarrollaré a continuación, en el análisis de los mecanismos de copy-paste presentes en la obra de Le Corbusier y sus equivalentes en la producción de OMA / Rem Koolhaas, un nuevo remake del maestro franco-suizo ${ }^{3}$.

\section{Mecanismos de copy-paste en Le Corbusier}

Le Corbusier, en esencia, sustenta su trabajo y pensamiento con el empleo de tres herramientas fundamentales que pueden leerse como mecanismos primitivos de copy-paste. La acción proyectual no consistirá en tomar literalmente una referencia extraída de un contexto inicial para ser insertada en un nuevo contexto dotándola de un nuevo significado, será algo más complejo. Las investigaciones que Le Corbusier realiza a lo largo de los años generan soluciones que se ensayan una y otra vez en sucesivas ocasiones. Su obra se entiende pues como un reciclaje continuo, en el que las soluciones se retoman, transforman, manipulan y adaptan a cada nueva ocasión: Le Corbusier se copia a sí mismo, pero altera tanto el origen que llega a inventar un nuevo tipo, una nueva organización que en numerosas ocasiones, poco tiene que ver con la referencia inicial. En Le Corbusier, los mismos temas de siempre aparecen re-elaborados una y otra vez.

Reducir en este texto a tres herramientas -historia ${ }^{4}$, fotografía y pintura- el análisis del trabajo y pensamiento de Le Corbusier es un poco temerario tratándose de su personalidad compleja, inquieta e interesada por todo cuanto a su alrededor ocurre, pero si es una buena manera de acotar y entender las influencias más importantes que encontramos en su obra que nos puedan ayudar a entender a nuestros contemporáneos. Qué duda cabe: abordar con la profundidad necesaria estos aspectos conduciría en realidad a realizar prácticamente una monografía sobre los mismos, que no es el caso. Quisiéramos entonces enunciar aquí algunos de los ejemplos presentes en la arquitectura lecorbuseriana que nos permitan establecer el legado de su obra en un ejemplo significativo de la arquitectura contemporánea, la arquitectura de Rem Koolhaas.

\subsection{Las referencias a la Historia y la reinvención de los tipos}

Jeanneret descubrirá en sus viajes de juventud el paisaje y las relaciones geométricas presentes en la naturaleza;

\footnotetext{
2 “¿Qué influencia tiene la historia de la arquitectura en tu obra? Probablemente tenga una influencia totalmente inconsciente, pero en el momento en que me interesé por la arquitectura, también lo hice por los fenómenos de la modernidad y la modernización: me interesaban al mismo tiempo el constructivista ruso Ivan Leodinov, Mies van der Rohe y la arquitectura norteamericana de los años veinte y treinta. Ese interés me permitió apoyar mi propio trabajo y otorgarle una dimensión crítica" Koolhaas, Rem en "Seminario, 21 de enero de 1991". En Rem Koolhaas Conversaciones con estudiantes. Barcelona: Editorial Gustavo Gili, 2002. pp 54. Título original Rem Koolhaas: conversations with students. New York: Architecture at Rice Publications - Princenton University Press, 1996.

3 "No se puede explicar de otra manera; Koolhaas es el Le Corbusier de nuestros días" Kipnis, Jeffrey en "El último Koolhaas”. En OMA / Rem Koolhaas 1992-1996. Madrid: El Croquis nº 79, 1996 pp.26.

4 "Recién acabáis de ver que arrastrado por la defensa de los derechos a la invención, he tomado como testimonio el pasado, ese pasado que fue mi único maestro, que continúa siendo mi único amonestador. Todo hombre ponderado, lanzado hacia lo desconocido de la invención arquitectónica, sólo puede apoyar verdaderamente su esfuerzo en las lecciones dictadas por los siglos; los testigos respetados por los tiempos poseen un valor humano permanente" Le Corbusier en Mensaje a los Estudiantes de Arquitectura, 10ª ed. Buenos Aires: Ediciones Infinito, 2001. pp.39.
} 
el color, la luz y la sombra; el mundo clásico frente al mundo medieval; el valor de lo volumétrico frente a lo superficial, lo lineal frente al claroscuro; la arquitectura como volumen o la arquitectura como estructura. Referencias todas ellas almacenadas en su memoria gracias a sus cuadernos de notas y apuntes y usadas en sus proyectos una y otra vez de manera inagotable hasta su muerte. Episodios vividos se entremezclan con detalles de construcción, relaciones humanas conviven con la naturaleza y el territorio; toda una amalgama de formas, recursos e ideas puestas a disposición de su pensamiento arquitectónico.

Es sobradamente conocida y mucho se ha escrito ya de una tipología que captó de manera muy significativa su atención, el monasterio, por lo que sólo haremos una breve reseña en este texto a dos de ellos: el monasterio cartujo de Galuzzo en el valle de Ema, cerca de Florencia, y el monasterio cisterciense de Le Thoronet en la Provenza francesa.

Visitado por primera vez en 1907 en su viaje a Italia, donde observó, dibujó y estableció las bases de lo que iba a ser su arquitectura, Jeanneret encuentra en el monasterio de Galluzo las ideas que le permitirán combinar lo privado y lo público en un mismo tipo. El esquema de sección con celdas en forma de 'L' que generan un patio en doble altura precedidas por un corredor cubierto y una galería superior con vistas a la naturaleza se emplearían, con variaciones, en las villas Citrohan, los Inmuebles villas o en las Unités d'Habitation, por citar algunos ejemplos; incluso aquélla pequeña ventana en el muro exterior de la casa de sus padres junto al lago Léman se inspira en las vistas que las celdas de los monjes ofrecían. El segundo de ellos, el monasterio de Le Thoronet, será propuesto por el padre Coutouier como modelo para levantar el futuro Convento de la Tourette. Muchos de los aspectos que aparecen en el monasterio cisterciense se reflejan, adaptados y transformados en el nuevo convento. Así, Le Corbusier re-elabora y re-compone la planta del monasterio original convirtiendo la pirámide del lavatorio en oratorio, el claustro no horizontal, irregular y con circulación anular, en corredores en forma de cruz por su centro en vez de su perímetro trasladando además los desniveles existentes en el claustro del monasterio a las pendientes de los corredores que conducen a iglesia del convento; repite el acceso en puente a la iglesia e incorpora en los niveles superiores las celdas que descubrió en Galuzzo. (1)

Los mecanismos de copiar y pegar en le Corbusier incluyen un paso intermedio de análisis, manipulación y transformación tan intenso que el proceso bien podría denominarse entonces como una operación compleja de copiar-interpretar-pegar. Como ya indicaría Colin Rowe acerca de su obra objetos y episodios son importaciones entrometidas y, aunque conservan las matizaciones de su fuente y su origen, consiguen también un impacto totalmente nuevo a partir de su contexto cambiado,5, es decir, Le Corbusier busca el tipo en la historia para después transformarlo, distorsionarlo o invertirlo ${ }^{6}$. Incluso, como ya se ha indicado, alterará tanto los tipos que han surgido de diferentes contextos históricos, que creará unos nuevos a veces irreconocibles.

\footnotetext{
${ }^{5}$ Rowe, Colin; Koeter, Fred: Ciudad Collage, Barcelona: Editorial Gustavo Gili, 1981. pp 139.

6 "Lo que hace Le Corbusier al diseñar los espacios públicos no es más que volver a crear la espacialidad de los lugares públicos de la Antigüedad, los lugares de representación y glorificación del colectivo que se encuentran en el origen de nuestra cultura y que constituyen el amago de nuestra tradición. A través de un filtrado conocimiento histórico, pero también de un sentido de abstracción - que presupone una de las más admirables conquistas del pensamiento moderno, la suspensión voluntaria de la sucesión y compartimentación temporal, así como de las subsecuentes explicaciones evolutivas y catalogaciones-, Le Corbusier hace uso de una visión sincrónica de los espacios públicos de la Antigüedad, vinculando el pasado al presente, estableciendo entre ellos contactos, superposiciones" Sequeira, Marta: Para um Espaço Público. Le Corbusier e a Tradição Greco-Latina na Cidade Moderna. Lisboa: Fundação Calouste Gulbenkian. Fundação para a Ciência e a Tecnologia, 2012.
} 

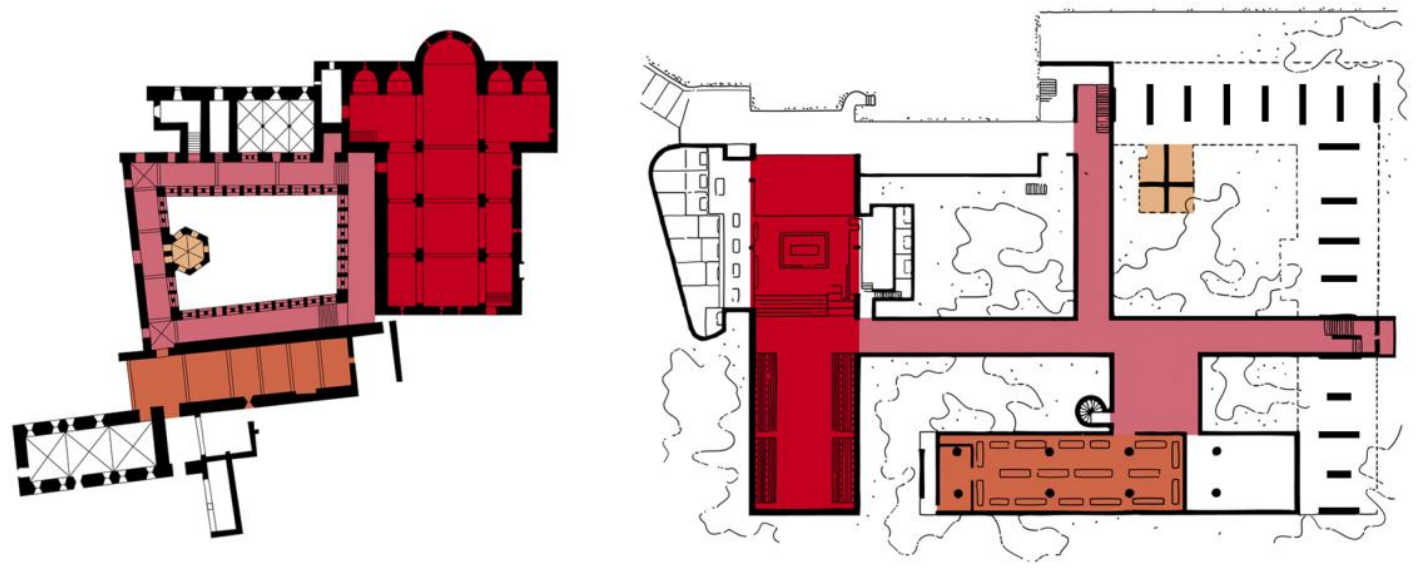

1. Plantas comparativas del Monasterio de Le Thoronet (izda) y del Convento de La Tourette, 1953-57 (dcha). Los colores identifican el cambio en la disposición de las diferentes partes del programa en ambos edificios.

Podemos ver, por ejemplo, como los pilotis blancos y delgados de sus villas de los años veinte se transforman en los rotundos soportes rugosos de hormigón de sus unidades de habitación. O como los brise-soleil que se emplean como elementos protectores de la fallida fachada de pan de verre empleada en la Cité de Refuge (París, 1929-33), se convierten en una verdadera pared perforada e independiente de la estructura, presente desde la primera idea del diseño, que introduce espacio en el borde y funde el exterior con el interior, en la Asociación de Hilanderos (Ahmedabab, 1951-54).

Pero Le Corbusier no sólo re-elabora elementos puntuales. Las mismas operaciones espaciales aparecen en su obra una y otra vez transformadas. Citamos como ejemplo la inserción de grandes vacíos en las fachadas. Estos vacíos rompen la simetría de la misma, estructuran su composición y, sobre todo, introducen ricos matices espaciales al incorporar sistemas de circulación en su interior. Son los casos de la villa Stein (Garches, 1927), el Palacio de Justicia (Chandigarh, 1951-55) y la Embajada de Francia en Brasilia (1964). Podríamos añadir el Pabellón L'Esprit Nouveau (París en 1925) que reproduce una de las células de vivienda de los Inmuebles villa de tres años antes o el Atelier Ozenfant (París, 1924) cuyo vacío en la fachada se muestra protegido por cerramientos de vidrio. (2)

Establecerá relaciones 'función-forma' y 'función-espacio' que no permiten disociar la una de la otra. Combinará los programas en un edificio, pero siempre los distinguirá de manera clara, o dicho de otro modo: no mezclará los programas en espacios únicos, aunque si los relacionará asociándolos cada uno a una forma determinada. De este modo Le Corbusier consigue una identificación ‘función-volumen' en un mismo objeto. Buscar una forma idónea para cada función le conduce inevitablemente a inventar, crear 'inventos' que expresen 
con claridad esta relación 'función-forma" ${ }^{97}$ Una ventana, por ejemplo, podrá estar compuesta por dos elementos: los ondulatoires -sólo para iluminar, y los aérateurs -sólo para ventilar.
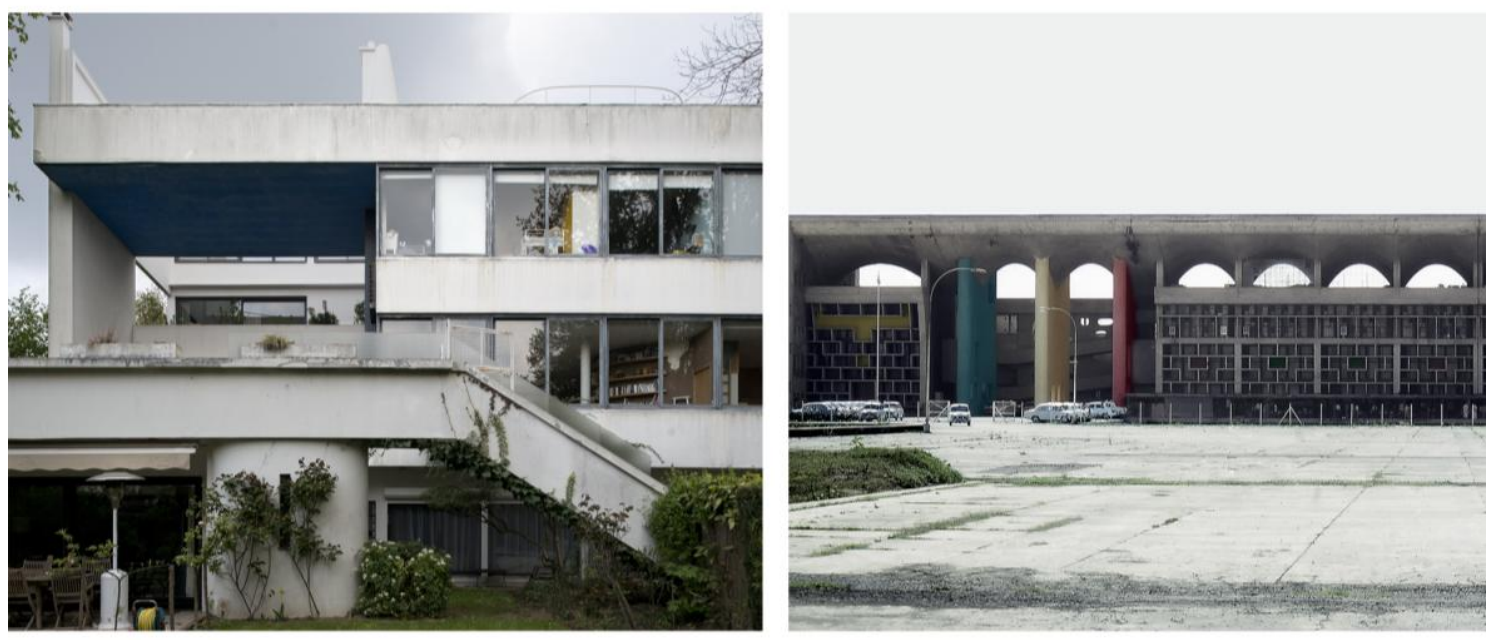

2. Fachadas comparadas con espacio vacío insertado en las mismas de la Villa Stein-de-Monzie "Les Terrasses", GarchesVaucresson 1926 (izda) y el Palacio de Justicia, Chandigarh 1952 (dcha).

\subsection{Las fotografías como divulgación de prototipos}

Le Corbusier separa los volúmenes para afirmarlos, para ser claros a la visión. Es decir, quiere que percibamos cada uno de los volúmenes completamente, separado de los otros, para poder descubrir y apreciar sus cualidades. Una vez el volumen, que adquiere cualidad de objeto gracias a su significación, se ha comprendido, se producirá un salto en la mirada hacia un nuevo volumen-objeto, con nuevas cualidades que introducirá nueva información, y así sucesivamente. Iremos recorriendo el espacio mediante las tensiones y las relaciones que los volúmenes y objetos crean entre sí, determinando nuestra posición y distancia a los mismos cada vez. Se entiende ahora mejor que una de las razones de separar el programa o la identificación de las funciones con objetos y volúmenes sea para lograr soluciones en las que una parte del programa no domine a la otra, para que cada objeto cuente con los significados que le son propios. Esta es una de las razones por las que Le Corbusier utiliza como mecanismo compositivo de manera preferente la fragmentación, la adición, sumar partes y añadir objetos, frente a la compacidad: copiar y pegar objetos en el espacio, pero cada uno de ellos con una intención y características que le son propias y que no se pierden cuando interactúa con sus vecinos. Los objetos contarán entonces en virtud de sus propiedades físicas, sus conflictos o sus acuerdos, algo que comprendieron bien los pintores cubistas ${ }^{8}$, usando sin embargo los objetos disociados.

Las cuidadas fotografías de su obra mostrarán estas relaciones, donde los objetos se irán sucediendo dentro de la composición fotográfica, estableciendo un recorrido en la mirada a través de ellos de la misma manera que recorreremos sus edificios. Así, Le Corbusier 'copia y pega' delante de cada uno de sus edificios su Voisin C7-

\footnotetext{
${ }^{7}$ Ver para más información Sáenz de Oíza, Francisco Javier: Le Corbusier, inventor de arquitecturas, Madrid: Colegio Oficial de Arquitectos de Madrid, 18 de diciembre de 1986. DVD (84m) Conferencia inaugural impartida por Oíza con motivo del ciclo de conferencias celebrando el centenario del maestro.

${ }^{8}$ Jeanneret, Ch. E.; Ozenfant, A: Después del Cubismo. Madrid: El Croquis Editorial, 1994. pp 12. Título original Jeanneret, Ch. E.; Ozenfant, A: Aprés le Cubisme. París: Edition des Commentaires, 1918.
} 
$10 \mathrm{HP}$ para tomar unas fotografías con las que pretende introducir en sus casas el rigor, la precisión y la economía que la industria del automóvil está desarrollando para los vehículos (3). Y es que las referencias a los logros técnicos de la época son constantes; en Vers une architecture podemos ver como paquebotes, aviones o automóviles se convierten en los estandartes con los que explicar la nueva arquitectura, y no existe reparo en mostrar el Partenón, en el que cada parte es decisiva, marca el máximo de precisión, de expresión ${ }^{9}$-dice Le Corbusier- junto a los prototipos del momento. La técnica aparece pues en Le Corbusier desde dos puntos de vista: como emblema y como prototipo. Rigor, precisión y economía se quieren trasladar a sus edificios. No existirán más piezas que las necesarias ni menos que las necesarias: se incluye justamente lo que hay que incluir. Así su definición de casa como machine à habiter no lo es tanto en el aspecto sino en la precisión, en el rigor con que una máquina está hecha. No le interesará a Le Corbusier la técnica por la técnica, como si se tratara de un recurso formal, sino todo lo contrario: es un instrumento para crear espacio. En este sentido, incorporar los automóviles en sus edificios no sólo como imágenes de propaganda, sino introducirlos físicamente en ellos, así como proponer nuevos trazados urbanos pensados desde el coche y la velocidad, tomará vital significación en su obra.
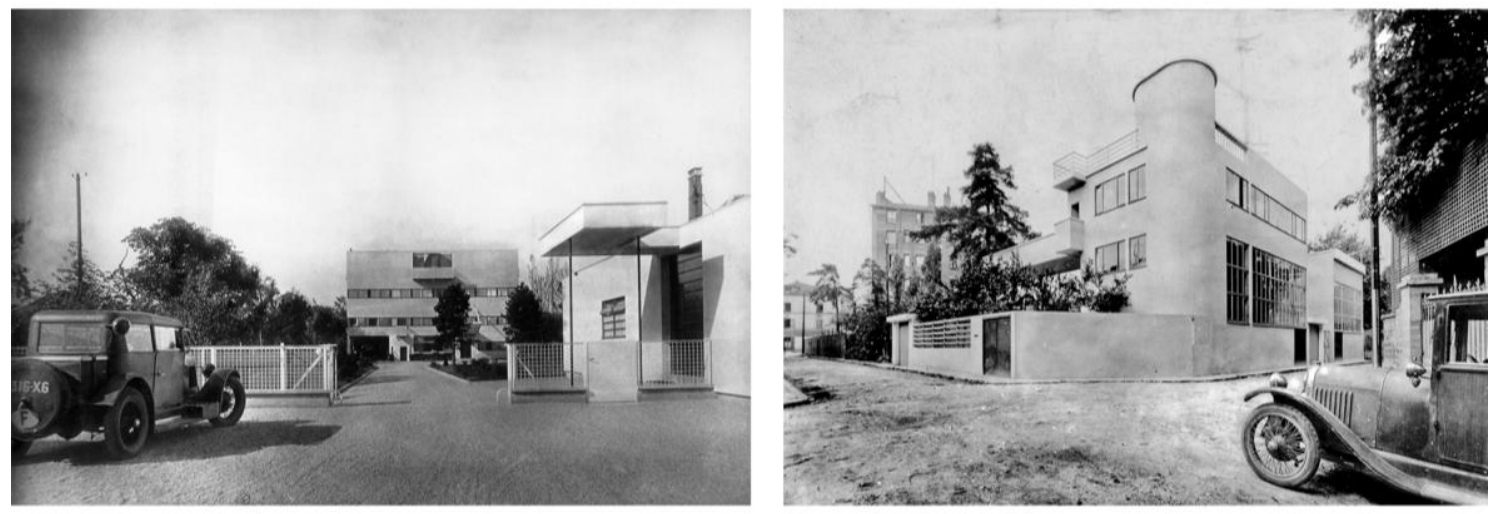

3. Copy-Paste del Voisin C7-10 HP propiedad de Le Corbusier en la Villa Stein-De Monzie "Les Terrasses", Garches 1927 (izda) y en las Maisons Lipchitz-Miestchaninoff, París 1923-24 (dcha).

\subsection{La pintura como laboratorio de arquitectura}

Yo soy conocido sólo como arquitecto; ninguno quiere reconocerme como pintor, aunque, incluso, es por el canal de la pintura por donde llego a la arquitectura ${ }^{10}$. Jeanneret entiende la pintura como pensamiento, como reflexión. Sus cuadros reflejan la importancia de los volúmenes, los huecos y la transparencia del espacio; reflejan el poder del objeto, el diálogo que se establece entre dicho objeto y el armazón que lo contiene. Su pintura es el verdadero laboratorio donde se ensayan las operaciones arquitectónicas que utilizará Le Corbusier en sus edificios: quien quiera conocer al Le Corbusier arquitecto no puede ignorar al Le Corbusier pintor. O dicho en los términos en los que este texto se escribe, Le Corbusier copia los descubrimientos que Jeanneret obtiene en sus cuadros y los pega en sus edificios.

\footnotetext{
${ }^{9}$ Le Corbusier: “Ojos que no ven” en Le Corbusier: Hacia una Arquitectura, 2ª ed. Buenos Aires: Editorial Poseidón, 1964. pp 111.

${ }^{10}$ Le Corbusier: Catálogo. Madrid: Museo Nacional Centro de Arte Reina Sofía, 1982. pp 112.
} 
En su etapa de formación (la Chaux-de-Fonds, viaje a Italia de 1907 y Viaje a Oriente de 1911) Jeanneret realiza acuarelas que capturan el paisaje, las relaciones entre la forma y el color, descubriendo la capacidad de éste de alterar la percepción de las cosas.

Instalado ya en París, Jeanneret crea junto al pintor Ozenfant y como respuesta crítica al Cubismo, el Purismo. Adoptará entonces el apodo de Le Corbusier para distinguir su trabajo arquitectónico del pictórico, si bien con el tiempo, terminará firmando los cuadros con el nuevo nombre adoptado. Los temas empleados son cotidianos, 'temas banales', que se irán convirtiendo con el tiempo en objetos de atracción poética. La línea concentra todo el valor formal: el contorno es el límite, un elemento muy denso; no es lo importante la forma que aglutina sino que tiene tanta importancia lo que incluye como lo que excluye. El color es rigurosamente 'encajado' en la línea y emplea una paleta sencilla de ocres, rojos y marrones $^{11}$.

El siguiente paso en su evolución será desligar el color de la línea: si primero se independizó el objeto, ahora se independizará el color, que es más fuerte, más unitario y opera por contraste. Plantea con el armazón simetrías que después rompe con la ayuda de los objetos. La retícula gobierna el orden del cuadro (las plantas en su arquitectura), aunque casi nunca está presente y se manifiesta de un modo parcial; los objetos serán capaces de crear espacio, de ahí que Jeanneret-Le Corbusier no sólo se interese por el objeto en sí mismo, sino por lo que alrededor del objeto se va creando. Los objetos se irán superponiendo, en grados que van desde la transparencia a la opacidad. Estos objetos tipo se asociarán generalmente a la introducción de curvas dentro de la planta. Definirán los cuartos de baño, cocinas, lavabos, las cajas de escalera y se tratarán como volúmenes-objetos aislados dentro del armazón. Estos volúmenes curvos moldearán de un modo fluido y dinámico el espacio, generando las circulaciones dentro de la planta, desplazando y distorsionando el resto de los espacios.

Quizás ahora comprendamos mejor los mecanismos con los que Le Corbusier opera, buscando los tipos en la historia, para tras alterarlos y modificarlos, insertarlos en un nuevo contexto, cuyo armazón compositivo oculto hay que buscarlo en la pintura. Y todo ello envuelto y cuidadosamente presentado con un potente discurso gráfico y verbal de divulgación y publicidad. Elementos fragmentados, sí, pero nada de juntos por azar. No se trata de una simple operación de copy-paste a la que podemos estar acostumbrados hoy en día. Se trata de una herramienta de composición arquitectónica y de organización programática y espacial compleja. No se tratan de copias sino de verdaderas citas a la historia o incluso a sí mismo; gracias a una 'lectura' atenta y cuidada de sus proyectos y edificios, podrán identificarse los elementos de origen, enriqueciendo con su descubrimiento el mensaje arquitectónico.

\section{Mecanismos de copy-paste en OMA / Rem Koolhaas}

La arquitectura que realiza OMA / Rem Koolhaas podría denominarse como un 'juego sabio de los volúmenes reunidos bajo la luz' disfrazados y entremezclados en la complejidad propia de los tiempos que vivimos, la de una arquitectura que debe reflejar nuestra sociedad. Para hacerlo posible, Rem parece 'calcar', paso a paso, la

\footnotetext{
${ }^{11}$ Ver para más información, Jeanneret, Ch. E.; Ozenfant, A: Después del Cubismo. Madrid: El Croquis Editorial, 1994. pp.12. Título original Jeanneret, Ch. E.; Ozenfant, A: Aprés le Cubisme. París: Edition des Commentaires, 1918. Sin duda en este manifiesto encontramos muchas de las claves de la pintura como campo de experimentación de la arquitectura. Desde la elección del tema, "un tema simple, un tema modesto" -leemos en el texto- hasta la subordinación del color a la forma "La idea de forma precede a la de color. La forma es preminente, el color no es más que uno de sus accesorios", pasando por la importancia de las proporciones, el uso claro de la geometría, concepción rigurosa o la admisión de ciertas deformaciones para restablecer la armonía.
} 
trayectoria lecorbuseriana, confundida y camuflada bajo hábiles mecanismos contemporáneos de "Copy-Paste".

Sin duda, si hay un arquitecto del que podamos aprender e investigar con profundidad es Le Corbusier: guardaba prácticamente todo, planos con facturas, objetos recogidos en la playa con libros, cuadros con pliegos de sus conferencias... una -irónicamente hablando- 'fuente de inspiración' inagotable para ser citado, homenajeado, imitado, re-interpretado, o sencillamente copiado por cualquiera de los arquitectos que le sucedieron.

La arquitectura de Koolhaas, como la de Le Corbusier, es una arquitectura de fragmentos, de suma de elementos para configurar un todo, una heterogeneidad en las partes que necesita, como en la arquitectura de Le Corbusier, de un mecanismo de unión arquitectónico. Copiar y pegar elementos -llámese citas, referencias o como quiera llamarse- produce en su arquitectura, inevitablemente, la decisión de eliminar el "detalle arquitectónico" entendido éste como el punto de unión entre una realidad copiada y una copia de otra realidad.

El Dios de Koolhaas no está en sus detalles, ni su menos es más.

Sencillamente el detalle se elimina de su arquitectura porque los fragmentos utilizados para lograr su arquitectura no concilian entre sí. En este sentido, preguntado por el papel que juegan las citas arquitectónicas, Rem Koolhaas contesta:

"Creo que estamos completamente inmersos en influencias. Y nunca he entendido el interés por identificar las citas en la arquitectura. Evolucionamos muy lentamente y estamos completamente influidos por el pasado, el remoto y el reciente. Siempre he sido incapaz de distinguir qué es una cita y qué es una simple influencia",12.

Curiosa respuesta, cuanto menos al comprobar que gran parte de su arquitectura está plagada de ¿citas? de la obra de Le Corbusier ${ }^{13}$. No se trata en este texto de desvelar todas, una por una, sólo indicaremos algunos ejemplos (4) que ayuden a explicar los argumentos que aquí se esbozan empleados por Rem Koolhaas para intentar la unión de los fragmentos, la integración de las partes: modificará la estructura (no sirve una estructura claramente miesiana de planos horizontales sustentados con columnas); confundirá los programas (huir de la identificación programa-forma tan propia de Le Corbusier); trabajará, investigará y alterará el tratamiento de ciertos materiales (como espejos y vidrios que contribuyan a romper el volumen de origen lecorbuseriano) y, finalmente, multiplicará los elementos de conexión (rampas, escaleras mecánicas, ascensores) para lograr un espacio en el que ninguna dirección sea predominante frente a otras (creará la que denomino 'multipromenade').

\footnotetext{
${ }^{12}$ Koolhaas, Rem: "Rem Koolhaas de la A a la Y". En El Croquis $n^{\circ}$ 134/135. Madrid: Editorial El Croquis, 2007. pp.384. Entrevista realizada por Beatriz Colomina.

${ }^{13}$ del Valle, Raúl. La Herencia de Le Corbusier en la Arquitectura de Rem Koolhaas. Composición y Adición de la Arquitectura Lecorbuseriana en la Arquitectura Contemporánea. Director: Alberto Campo Baeza. Universidad Politécnica de Madrid, Departamento de Proyectos Arquitectónicos. Madrid, 2006.
} 

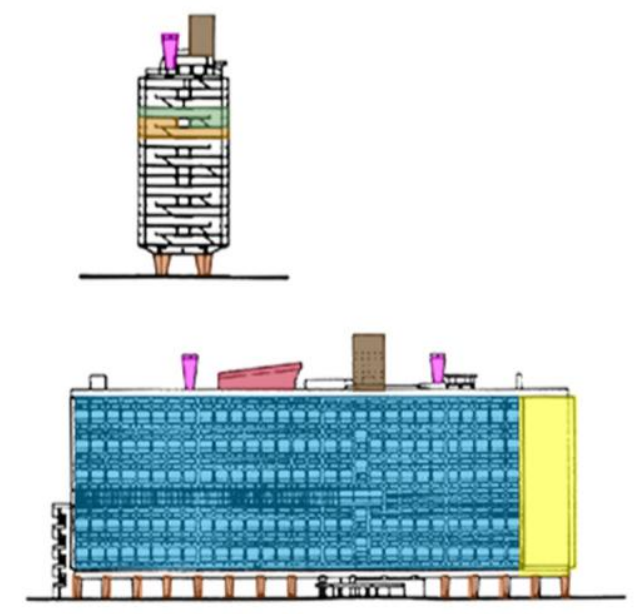
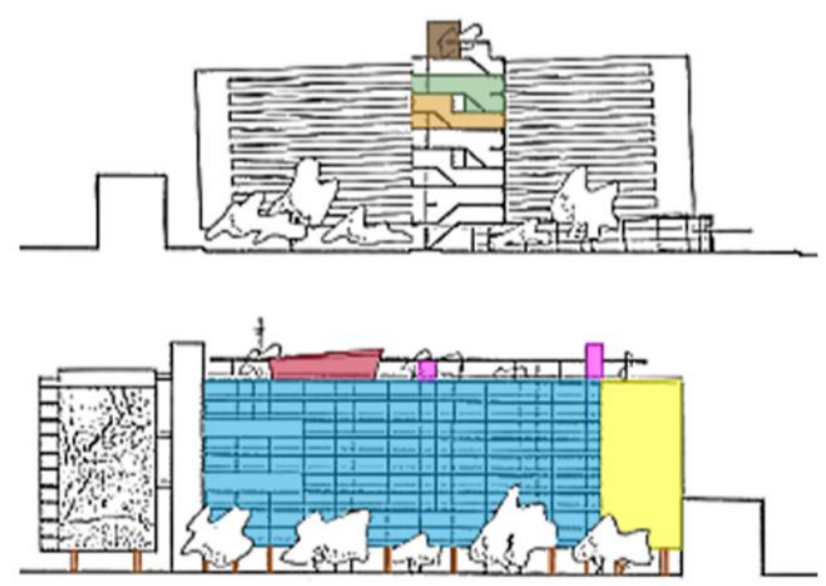

4. Copy-Paste de la Unité d'Habitation, Marsella 1946-1952, de Le Corbusier (izda) en el proyecto Torenstraat, La Haya 1985, de OMA / Rem Koolhaas (dcha). Los colores identifican la coincidencia de los diferentes elementos y partes del programa en ambos edificios.

\subsection{Destrucción de la Estructura}

Koolhaas irrumpe en el panorama arquitectónico a partir de una exhibición en el MoMA de Nueva York a finales de los años ochenta denominada 'La Deconstrucción'. Deconstruvist Architecture ${ }^{14}$ se mostró entonces acompañada de pintura y escultura perteneciente a las vanguardias rusas. Muchos de los aspectos que defiende la Deconstrucción y con los que se hace doctrina ya están presentes o, al menos presentados, en proyectos lecorbuserianos. Le Corbusier ya trabajó nuevos principios de desarrollo de la planta: en la Ciudad Contemporánea para tres millones de habitantes (1922) mantiene un esquema concéntrico, de jerarquías muy marcadas, de expansión del centro hacia el exterior; en la Ville Radieuse (1940) abandona el centro como generador y propone una ciudad organizada por bandas paralelas asociadas a diferentes usos, que pueden extenderse libremente; también encontramos en Le Corbusier a través de su fascinación y admiración por el plano horizontal de la Acrópolis (sobre el que se posan diferentes templos) o el plano de la Plaza de los Milagros de Pisa (sobre el que se sitúan el Campo Santo, el Baptisterio y la Torre inclinada) los ejemplos en la historia para poder establecer una disposición libre de objetos sobre una extensión determinada en sus arquitecturas; incluso el Hospital de Venecia (1965) se organiza en base a una trama, una malla, que puede extenderse por todos los lados si no hay dificultades de expansión.

\footnotetext{
${ }^{14}$ En ella, el trabajo de Koolhaas aparece junto al de Bernard Tshumi, Frank O. Gehry, Peter Eisenman, Daniel Libeskind y Coop Himmelblau entre otros. Con la Deconstrucción se pretende manifestar la no-estructura y poner en duda los modos de conexión habituales entre las partes. Los edificios son concebidos como estímulos para actividades humanas de índole imprevista e indeterminada.
} 

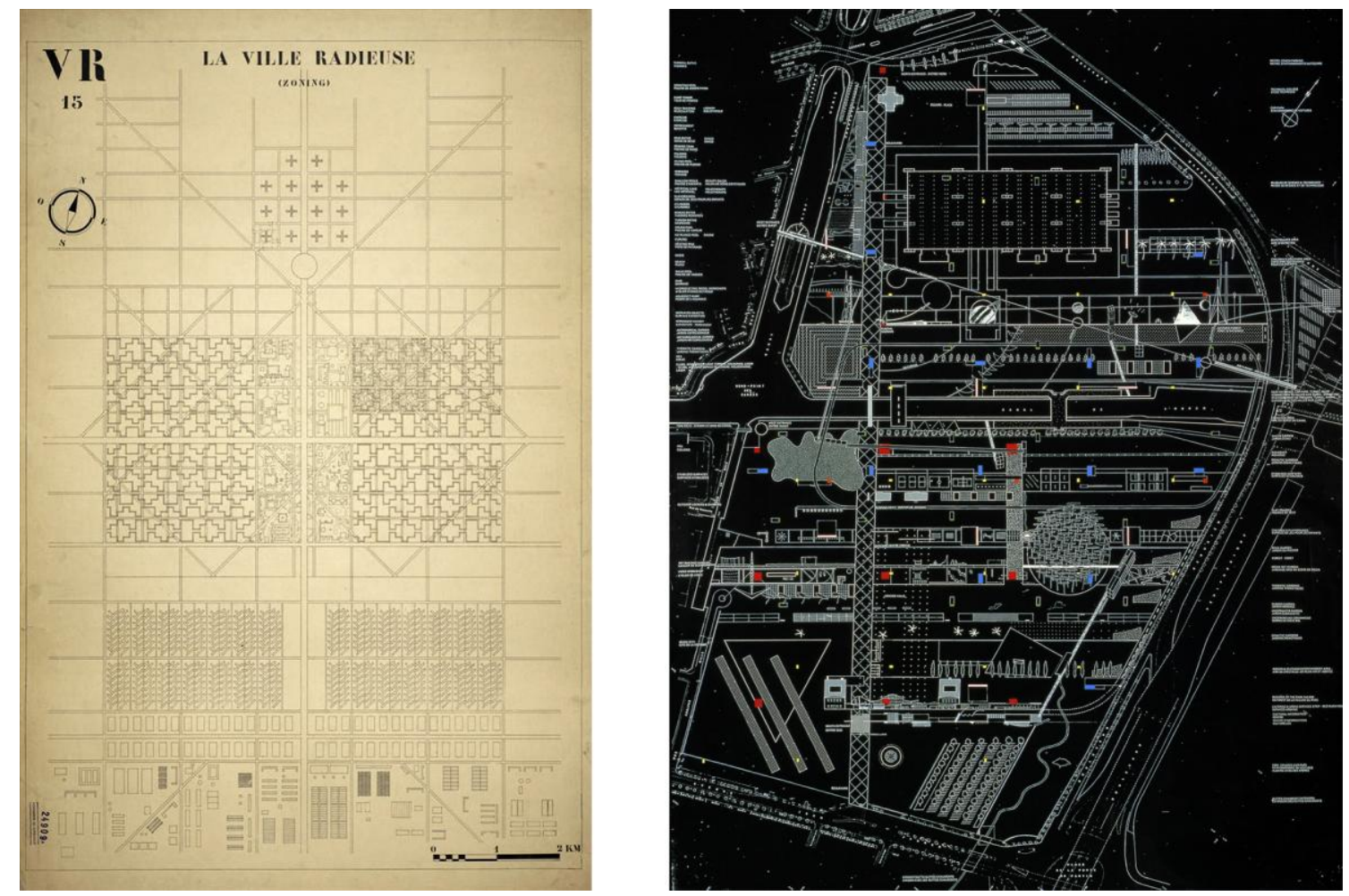

5. Le Corbusier, Villa Radiuse 1940, planta (izda) y OMA / Rem Koolhaas, Parc de La Villete, París 1982, planta (dcha).

Así pues, desarrollos tipo 'mat-building', con disposición libre de objetos sobre bandas, tramas o mallas, tan característicos del Deconstruvismo existen ya en Le Corbusier y son utilizados por Koolhaas en su proyecto del Parc de La Villette (París, 1982). Koolhaas nos dice que en el parque de La Villette profundiza en el tema de la congestión, ingrediente clave de cualquier proyecto o arquitectura metropolitanos. Es el primer proyecto en el que se investiga sobre este tema después de los estudios sobre Nueva York. (5) Para Koolhaas la arquitectura está muy ligada a la acción y al programa. Destruir la estructura es destruir la arquitectura misma, y la Deconstrucción no puede destruir aquella estructura que precisamente construye. Por esta razón Koolhaas intentará reducir al mínimo a la arquitectura.

La arquitectura de Koolhaas se conforma por tanto con la representación de la misma, no le interesa ni la construcción ni el empleo de los materiales más allá de su poder representativo de las ideas que detrás se esconden.

Si recurrimos de nuevo a la pintura elaborada en sus inicios por Jeanneret y evolucionada en la pintura de Le Corbusier recordamos que los elementos están ensamblados en una trama oculta, donde línea y color van asociados, para comenzar con el paso del tiempo a hacerse independientes, abandonando la trama reguladora e independizándose las líneas de los colores. En las naturalezas muertas, la composición de los objetos presenta sobre el mismo plano del cuadro dos visiones distintas y complementarias de los mismos: por un lado los alzados y por otro, las plantas dibujadas en continuidad con aquéllos. Se produce un cambio entre planos perpendiculares de manera continua. Le Corbusier no trasladará sin embargo esta idea a la arquitectura: el cambio de planos no se produce de manera continua, es decir, mantendrá la independencia de los planos horizontales y verticales, no estableciendo transformaciones de un elemento en otro como si hará Koolhaas.

Los suelos inclinados y, más aún, los suelos que se convierten en paredes verticales y quizás de nuevo en horizontales surgen no sólo por hacer "física" la continuidad espacial, en una extensión a una superficie mayor de la rampa lecorbuseriana, sino que surgen para representar conceptualmente y para disolver la estructura en una relación figura-fondo. 


\subsection{Simultaneidad de Programas}

Hubo un tiempo en que las funciones estaban asociadas a las estructuras que las permitían y dichas funciones determinaban a su vez esas estructuras. Existía una relación clara espacio-función: las cosas son lo que quieren ser, decía Kahn. Con el tiempo, podemos asignar a unos espacios pensados para una serie de actividades otras que en principio, no estaban destinadas allí: comienza a aparecer el espacio flexible. Y las cosas pueden ser lo que quieren ser, pero también algo más. Las estructuras se hacen más capaces para acoger diferentes usos. Pero claros y definidos: lo que antes era un hospital ahora puede ser un museo, y lo que antes era una fábrica ahora se convierte en un centro cultural. Pero no todos los usos permiten los cambios con la misma flexibilidad de igual modo que no todos los espacios son capaces de permitir todos los usos. El programa se convierte entonces para algunos arquitectos en un nuevo material para definir la arquitectura, que impone a ésta sus leyes y relaciones, dictando las decisiones del proyecto: estudiar los programas, con numerosos datos e infinitas relaciones posibles donde todo tiene cabida se convierte en un nuevo modo de afrontar el diseño del espacio desde el programa.

El Ayuntamiento de La Haya (1986) constituye el primer ejemplo en el que Koolhaas intenta resolver un proyecto desde la inestabilidad programática, de hacer arquitectura con programas y no con formas. Las plantas se componen de bandas paralelas que deslizan entre sí, manipulando una trama regular de pilares existente allí donde sea necesario gracias a la inserción de unos objetos-programa (llenos o vacíos), articulándose los diferentes espacios por medio de rampas, escaleras o ascensores. Plantas que recuerdan el modo organizativo de Le Corbusier de recintos enlazados por los espacios intermedios, o alterados por la manipulación que unos ejercen sobre los otros.

La libertad con la que Koolhaas pretende manejar los programas, con la excusa de reflejar cierta incertidumbre o inestabilidad, se traduce también en la casa Y2K de Rotterdam y la Casa da Música de Oporto, en las que un salón se convierte en una sala sinfónica, y diferentes estancias de la vivienda pueden ser diferentes espacios de un edificio público. Estamos quizá ante el ejemplo más evidente del copy-paste llevado al extremo: el de copiarse a si mismo. La traslación del proyecto existente es tan literal que el propio Koolhaas menciona el desconcierto de los miembros de su estudio "no podían creer que fuésemos tan cínicos"15 ante el aparente oportunismo del cambio de escala de la casa para convertirla en auditorio.

Le Corbusier sin embargo, re-elaborará los programas buscando los tipos en la historia para después transformarlos, distorsionarlos o invertirlos como ya hemos expuesto y buscará una forma para cada función. La suma de elementos necesitará de varios mecanismos para unir y enlazar lo disperso, como son las calles creadas entre los edificios, el Modulor y los trazados reguladores como mecanismo de verificación, la división en estratos horizontales independientes que permiten ser intercambiados entre sí y que se conectan por un conjunto de escaleras y rampas, etc.

\subsection{Materialidad desmaterializada}

El empleo que los materiales hace Rem Koolhaas está lo más alejado posible de Le Corbusier, no haciendo gala de esa 'deshabillé' a la que se refería Sota ${ }^{16}$ ni, por asomo, al uso y empleo que de los materiales hace Mies van der Rohe. Tampoco el detalle constructivo, como ya hemos indicado, servirá para unir los fragmentos del copy-

\footnotetext{
${ }^{15}$ Koolhaas, Rem en Fernández-Galiano, Luís: “La vida de las formas”. En Arquitectura Viva $n^{o}$ 73. Madrid, 2000. pp. 26

16 “Admiré siempre en la obra de Le Corbusier su deshabillé, esa perfección de dentro, esa elegancia imposible, tan ligada a esa imperfección aparente" De la Sota, Alejandro en "Le Corbusier". En Alejandro de La Sota. Madrid: Ed. Pronaos, 1989. pp. 223.
} 
paste. Sirva de ejemplo el Congrexpo de Lille (1990-1994) en el que Koolhaas recurre al empleo de un hormigón con un acabado que quiere ser una plementería, que se gira además cuarenta y cinco grados y que resuelve también pilares y pilastras indistintamente. Una falta de interés en los detalles que podemos apreciar también en el modo de marcar las juntas o incluso en la manera de diseñar la salida de los conductos: meros agujeros hechos con taladros allí donde es necesario, en la chapa o en el hormigón. (6)

Tampoco el empleo que de los materiales hace Rem Koolhaas en el McCormick Tribune Campus Center, ITT (Chicago, 2003) muestra un especial interés o respeto por el material y el modo de construir. Como escribe Javier Mozas: 'Koolhaas ha rebanado las mejillas de un Mies sonrojado y ha ensuciado el candor de la verdad agustiniana con materiales abyectos. El puritanismo miesiano sobre el acero, con esas esquinas bien perfiladas y dibujadas con primoroso candor, es transformado, por una carrera hacia lo genérico, en la construcción con un material mucho más trasgresor y abyecto como es el panel ligero de cerramiento. Un panel traslúcido de color naranja, un material chillón que recuerda a los restaurantes de comida rápida, resaltando aún más, en un juego perverso de contraposiciones, la nula utilización que Mies hacía del color. El panel barato que emplea Koolhaas en el Centro de Estudiantes del IIT, destroza el religioso puritanismo de Mies respecto a los materiales $^{, 17}$.
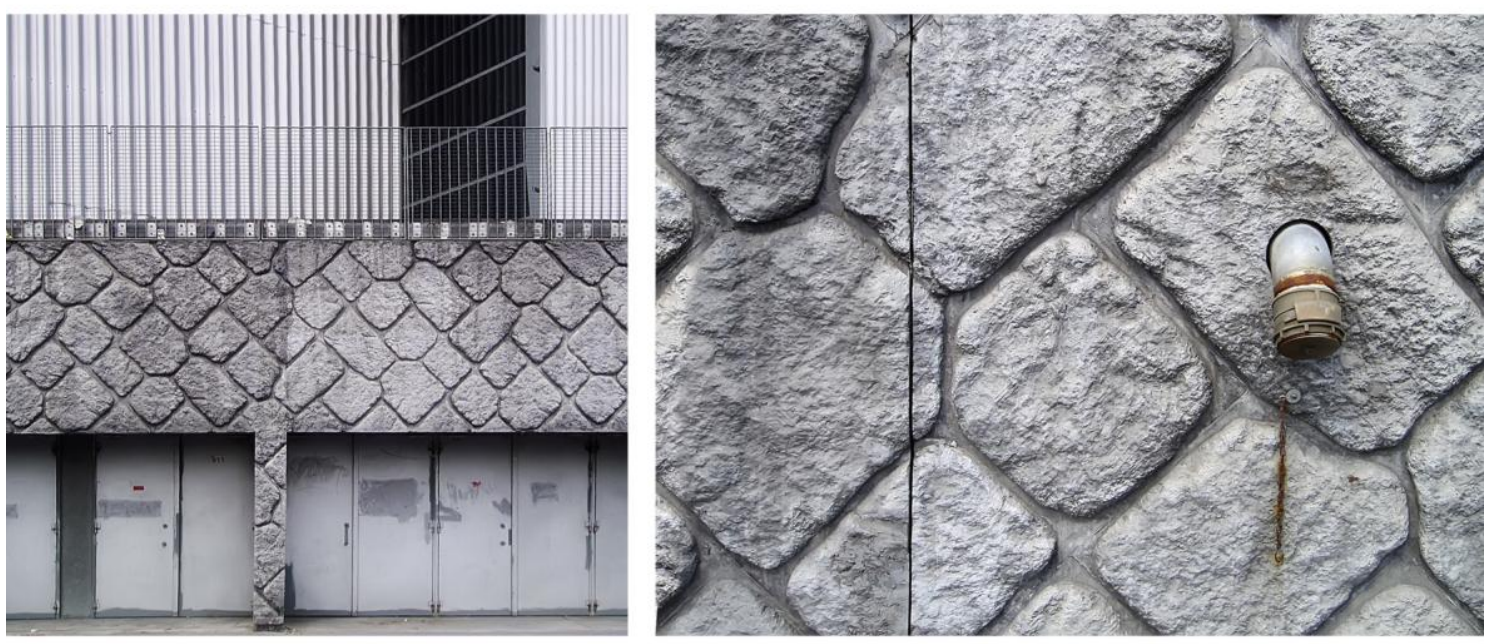

6. OMA / Rem Koolhaas, Congrexpo, Lille 1990-1994. Fachada y detalle.

\subsection{Multi-Promenade}

Le Corbusier estructura los diferentes espacios de sus edificios mediante la adición. Podrá quizás pensar y trabajar las diferentes piezas de manera aislada e independiente, pero al analizar el resultado comprobaremos que en verdad, esas piezas, no están ni tan aisladas en sus funciones ni son tan independientes en sus espacios. Utilizará el mecanismo arquitectónico de la rampa para unir y conectar, para establecer relaciones entre espacios y programas. Empleada en la mayoría de sus proyectos, las rampas no siempre se utilizarán del mismo modo y por tanto, no siempre adquieren las mismas connotaciones espaciales. Este mecanismo de conexión, vendrá muchas veces acompañado de escaleras y planos inclinados, y todos juntos, establecerán un complejo sistema que otorgara unidad al complejo armazón que constituye su idea de cómo debe ser la arquitectura.

\footnotetext{
${ }^{17}$ Mozas, Javier: "La condición moral de los materiales”. En A+T Nueva Materialidad. Madrid, 2004. pp. 4.
} 
La promenade architecturale en definitiva, y dicho de manera sencilla, no es más que establecer una relación entre el hombre y el espacio a través del movimiento (la percepción, los itinerarios, las perspectivas) y toma con la rampa un protagonismo esencial. La visión lecorbuseriana no es focal, ni central, ni entendida de un modo clásico partiendo de un punto fijo en el espacio desde el que se percibe y entiende el mismo: con la incorporación de la rampa, transforma lo que antes era un recorrido horizontal en un recorrido mixto horizontalvertical.

Podríamos preguntarnos si la arquitectura se entiende, se asimila o se reconoce mejor en una posición fija o en movimiento. Caminamos por los espacios, pero nos detenemos cuando queremos observar algo con detenimiento e incluso nos sentamos. La arquitectura se transmite en la mayoría de las veces a través de una imagen fija, desde un punto de vista fijo, que es el de la cámara fotográfica, y a pesar de las nuevas tecnologías y nuevos medios de expresión y difusión pocas veces se recurre a imágenes en movimiento para transmitir los espacios creados, confiando en la fotografía para mejor expresar y transmitir sus intenciones en un determinado edificio.

En la obra de Rem Koolhaas, como en la de Le Corbusier, el movimiento es fundamental. Pero no lo es por el hecho de desplazarse de un sitio a otro, ni tampoco por pertenecer a una promenade pues el movimiento de Koolhaas no se entiende al modo lecorbuseriano como un movimiento que se apropie del espacio, sino todo lo contrario. Es importante el movimiento en Koolhaas por las conexiones que crea, por los puntos que une y enlaza. En movimiento por los espacios de sus edificios apreciamos y entendemos la fragmentación de cómo están hechos, las partes que se suman, independientes, puestas juntas, apreciamos las partes copiadas y pegadas. Suele ser un movimiento condicionado por la geometría impuesta. El equivalente a la rampa en la arquitectura de Le Corbusier en la arquitectura de Rem Koolhaas es la "escalera mecánica" que, en esta idea de establecer las relaciones y conexiones entre Koolhaas y Le Corbusier, hace que yo la denomine 'rampa mecánica': un mecanismo que permite el movimiento rápido por el espacio además de alcanzar dos puntos situados a diferentes alturas sin los desarrollos excesivos que el empleo de una rampa con pendientes admisibles requeriría. En el juego del despiste, Koolhaas multiplicará los elementos de conexión que se producen en sus edificios (como hace Le Corbusier), ofreciendo diversas alternativas a los recorridos, disolviendo el movimiento en el espacio en un intento de conseguir lo que Le Corbusier logra con su promenade architecturale: unir lo desunido, enlazar la disparidad de las partes y programas entremezclados en ellas.

\section{Conclusiones}

Le Corbusier inicia realmente su formación con los viajes de Jeanneret. Las enseñanzas de L’Éplattenier en La Chaux-de-Fonds fueron el punto de partida de un verdadero conocimiento adquirido al recorrer Europa, el Mediterráneo, y las grandes obras de la cultura clásica levantadas en torno a él. Inseparable de su cuaderno de viajes, anota, escribe y dibuja impresiones que le marcarán toda una vida. Con el dibujo como principal medio de expresión capta la esencia de todo cuanto ve, sintetiza complejas organizaciones en sencillos esquemas que interpreta una y otra vez en sus edificios. Hoy se viaja por Internet. Y el dibujo ha sido sustituido por la cámara fotográfica digital que atrapa lo que miramos, pero no nos permite ver. Vivimos un momento en el que predomina, frente a la esencia de las cosas, su imagen. Podemos ahora revisar algunas de influencias en el maestro tomadas de su verdadera fuente de inspiración, la Historia, y ver, con algunos ejemplos, cómo el proceso se repite en la obra de Rem Koolhaas, sin duda uno de los arquitectos más representativos de nuestro tiempo, al tomar las referencias, digamos 'prestadas' de la obra de Le Corbusier. Sobran las palabras. 
Podríamos leer toda la arquitectura de Le Corbusier como un copiar (de la historia) y pegar (las referencias intelectuales y complejas) operaciones que se repiten, una y otra vez en sus edificios. Y podemos ir más lejos: en toda la historia de la arquitectura existe un 'copy-paste' más o menos complejo, de unos estilos a otros (postmodern, neo-gótico, re-nacimiento), de unos arquitectos a otros, de unos edificios a otros. 'Copy-Paste' puede entenderse entonces como un proceso en el que un elemento específico es extraído de su ubicación original, transformando o no sus cualidades de escala, proporción y tamaño, y es insertado en un nuevo elemento del que comienza a formar parte, aportando sus cualidades a la formación de un 'todo' discontinuo, donde puede resultar reconocible o irreconocible, en función del grado de abstracción del proceso de inserción. (7)
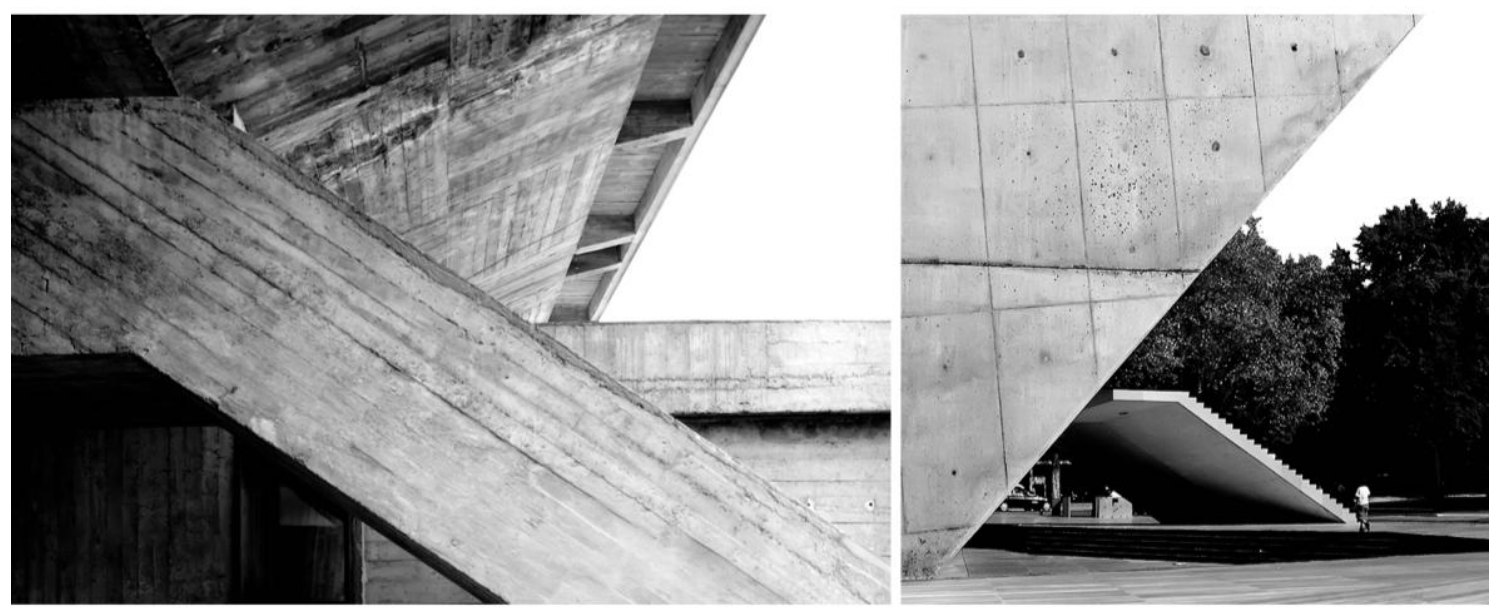

7. Copy-Paste de la Unité d'Habitation, Marsella 1946-1952, de Le Corbusier (izda) en la Casa da Música, Oporto 20012005, de OMA / Rem Koolhaas (dcha).

Esta idea, que no es nueva y que comúnmente se ha denominado por quien la practica 'referencia o cita histórica' aceptándose su uso, pues dotaba al resultado de cierta 'intelectualidad' en función del grado de complejidad de la referencia, hoy se ha convertido en un proceso más inmediato, donde no importa tanto lo intelectual sino la capacidad de resolución que dicha inserción pueda provocar. Este es el peligro que la acción de copiar y pegar introduce.

Si bien antes el proceso de 'copiar' (imitar, referenciar, homenajear, rememorar, citar) pretendía precisamente crear referencias con el pasado, con las grandes obras que se tomaban como modelos para proseguir el proceso de creación arquitectónica, hoy, el proceso de 'copiar' pierde las referencias del modelo: el contexto desaparece si es necesario, y en cierta media, se pretende 'esconder' el original dentro de un collage de elementos que se mezclan y confunden. Un último y aplastante ejemplo lo acabamos de ver en la reciente Biennale di Venezia de Arquitectura, dirigida por Rem Koolhaas. Bajo el título de Elements, la arquitectura se descompone, se divide, se fracciona, se desmorona, se destruye... puertas, ventanas y escaleras; fachadas, muros o suelos se estudian y tratan de manera independiente. Los elementos que forman la arquitectura pierden su contexto para crear un collage de partes, inconexas e independientes.

Ante este panorama del que la arquitectura no es ajeno, Le Corbusier puede entenderse, de nuevo, como una referencia a seguir. Porque su obra está llena de modelos y ejemplos que se copian y re-copian una y otra vez, pero siempre con un significado distinto, y siempre dejando la posibilidad de llegar a la fuente original de referencia que ha sido utilizada. Quizás entonces, tomando a Le Corbusier como modelo, el Copy-Paste se convertiría no en un peligro sino en un mecanismo eficaz para dar respuesta a la misma pregunta qué, siglo tras siglo, se han planteado los arquitectos una y otra vez: fabricar una visión propia de nuestro mundo, porque sólo en la medida que seamos capaces de interpretarlo, podremos cambiarlo. 


\section{Procedencia de las imágenes}

1. (izda) Extraída de 'Le Corbusier. Ideas y Formas’, p183. Policromía Raúl del Valle

(dcha) OC 1952-57 p45, extraída de 'Le Corbusier. Oeuvre Complète. Volumen 6. 1952-57' Edición Girsberger, 1957. CFLC-ADAGP. Policromía Raúl del Valle

2. (izda y dcha) CRaúl del Valle

3. (izda) L1(10)14 fotografía de Charles Gérard CFLC-ADAGP

(dcha) L1(6)31 fotografía de Charles Gérard @FLC-ADAGP

4. (izda) CFLC-ADAGP. Policromía Raúl del Valle

(dcha) Image courtesy OMA @OMA. Policromía Raúl del Valle

5. (izda) Plan FLC 24909A @FLC-ADAGP

(dcha) Image courtesy OMA COMA.

6. (izda y dcha) (ORaúl del Valle

7. (izda y dcha) @Raúl del Valle

\section{Bibliografía}

De la Sota, Alejandro: “Le Corbusier”. En Alejandro de La Sota. Madrid: Ed. Pronaos, 1989.

Del Valle, Raúl. La Herencia de Le Corbusier en la Arquitectura de Rem Koolhaas. Composición y Adición de la Arquitectura Lecorbuseriana en la Arquitectura Contemporánea. Director: Alberto Campo Baeza. Universidad Politécnica de Madrid, Departamento de proyectos Arquitectónicos. Madrid, 2006.

Fernández-Galiano, Luís: “La vida de las formas”. En Arquitectura Viva n 73. Madrid, 2000.

Jeanneret, Ch. E.; Ozenfant, A: Después del Cubismo. Madrid: El Croquis Editorial, 1994.

Koolhaas, Rem: Rem Koolhaas Conversaciones con estudiantes. Barcelona: Editorial Gustavo Gili, 2002.

Koolhaas, Rem: Rem Koolhaas 1992-1996. Madrid: El Croquis no 79, 1996.

Koolhaas, Rem: El Croquis $n^{\circ}$ 134/135. Madrid: Editorial El Croquis, 2007.

Le Corbusier: Mensaje a los Estudiantes de Arquitectura, 10ª ed. Buenos Aires: Ediciones Infinito, 2001.

Le Corbusier: Hacia una Arquitectura, 2ª ed. Buenos Aires: Editorial Poseidón, 1964.

Le Corbusier: Catálogo. Madrid: Museo Nacional Centro de Arte Reina Sofía, 1982.

Mozas, Javier: "La condición moral de los materiales”. En A+T Nueva Materialidad. Madrid, 2004.

Otiniano Pulido, C: “La guerra de las universidades contra el copy-paste”. En Economía, El País. 8/06/2015.

Rowe, Colin; Koeter, Fred: Ciudad Collage, Barcelona: Editorial Gustavo Gili, 1981.

Sáenz de Oíza, Francisco Javier: Le Corbusier, inventor de arquitecturas, Madrid: Colegio Oficial de Arquitectos de Madrid, 18 de diciembre de 1986. DVD.

Sequeira, Marta: Para um Espaço Público. Le Corbusier e a Tradição Greco-Latina na Cidade Moderna, Lisboa: Fundação Calouste Gulbenkian. Fundação para a Ciência e a Tecnologia, 2012. 